\title{
Innovative design of campus green spaces in the context of the "One Belt, One Road" and the digital use of Silk Road elements
}

\author{
Weile Jiang ${ }^{1, *}$ Mingcong Zou ${ }^{1}$ \\ ${ }^{1}$ School of Humanities and Social Sciences, Xi'an Jiaotong University Xi' an Jiaotong University, Xi'an, China
}

\begin{abstract}
In recent years, the strategic development concept of "the Belt and Road Initiative" has been put forward in China, which brought new significance and connotation to the development of "Silk Road" in this era of globalization, digitalization and knowledge. As the starting point of the Silk Road, Xi 'an is also an international cultural metropolis that is further building and promoting economic prosperity and development. This special location has entrusted its unusual historical task. As the campus of Xi 'an Jiaotong University, the scientific and Technological Innovation Port in western China, located in Xi 'an, needs the rendering and influence of Silk Road culture. Therefore, in order to make teachers and students consciously inherit and appreciate the Silk Road culture, it is of great significance to make the diversity of the Silk Road culture reflect on the campus and create a unique campus landscape.

The paper is divided into five chapters. Firstly, it summarises the development of Silk Road culture from different dimensions such as era, level and region, extracts different categories of elements, summarises them with the analysis of the research of Suzhou Silk Museum, and discusses how to apply these elements to campus landscape design. Take the landscape of the green space in the east part of the Innovation Port as a design sample, combine with the field investigation and analysis, further outline the shape, path, colour, material and plant elements, follow the principles and principles of campus landscape design, enumerate the plant elements with data, explore new application methods, define the design concept with characteristics, from the road, culture and ecological landscape configuration, characteristic silk road culture elements in the whole site. In this way, the Silk Road culture can be inherited, history can embrace the future, and a distinctive campus landscape can be created that adapts to the new trends of the times.
\end{abstract}

\section{From the silk road to the Belt and Road Initiative}

In his book The Silk Road: A New History of the World, Peter Francopan argues that "we tend to think of globalization as a peculiar symptom of social progress, but more than two thousand years ago, globalization existed. It not only brought opportunities and challenges, but also had a great impact on technological progress."2This work shows that at the time of "globalization" go by "path" contains the "silk road", the road to make is the result of Chinese silk is famous international and Chinese culture, Buddhism, Christianity and Islam also generates a concept of faith, and spread to affect all over the world as a civilization based by the road between east and west and blend, mainly including ancient Babylon, ancient Egypt, ancient India, ancient China and ancient Greece and Rome. The history of the Silk Road is like a short and rich general history of the world or a condensed and complex brief history of mankind, which tells the past and future of the world.

In the second half of the early 19th century, the history of the Silk Road, a key part of the study of the world's ancient civilization, was at that time only a very conceptual idea, akin to an economic and trade customs route. With the two major archaeological excavations of the civilization of the ethnic groups in the western regions of China and the civilization of Marine organisms in China in the new century, people have gradually discovered that there are still many routes of the Eurasian continent with China as the core and ocean routes of the Asian ocean as the core. 5In world history, many human societies and civilizations were born along these trade routes. In the silk Road, the state of free and equal communication among human civilizations came into being, thus giving rise to the idea of "Silk Road civilization".

In 2013, the "the Belt and Road Initiative" was launched by the state. The keyword "One Belt And One Road" has been entrusted by us with more diversified connotations, which can be broadly understood as the five links: strategic communication, transportation connectivity, unblocked commerce and trade, currency circulation and people-to-people connectivity. The integration of land, sea and air from zero to one, as well as the integration of economy and society, indicates that the Chinese people have changed from a free civilization to a basic law of exchange and mutual learning and their understanding of the world. It also indicates that the uniqueness and independence of culture have been

\footnotetext{
${ }^{*}$ Corresponding author: jiangwl@xjtu.edu.cn
} 
elevated to a new level of spontaneity and pride, which has also been recognized internationally. At the same time, today's "Belt and Road" is the return of "Silk Road", which means that diverse civilizations and rich cultures will appear again in the future. Diversity of civilizations is the prerequisite for cultural prosperity. In order to protect and inherit such diversity as far as possible, the modern Belt and Road Will spare no effort to realize the sustainable development of civilizations and cultures, learn from and communicate with each other, and build a new pattern of globalization of human destiny.

\section{Cultural exchange and development of the Silk Road}

Wasteland, gobi, oasis, sea, the Silk Road is fantastic and mysterious. On this road, the contact, exchange and integration of civilizations have boosted the progress of historical civilizations and influenced the course of world civilization.

\subsection{The development of Silk Road culture in different periods}

\subsubsection{During Qin and Han Dynasty.}

Today, silk from the Spring and Autumn and Warring States periods in China has been unearthed in Stuttgart in southwestern Germany and the Crimean Peninsula in eastern Europe. The mythical story of King $\mathrm{Mu}$ of the Zhou Dynasty passing through the Hexi Corridor on the Silk Road to visit the Queen Mother of the West and present her with beautiful jade and silk is recorded in the "Legend of Mu Tianzi". This legend not only pioneered the development of the Silk Road but also reflected the intermingling of cultures on the Silk Road. During the Qin Dynasty and the early years of the Han Dynasty, the Xiongnu almost monopolized the road to the West, and naturally also monopolized the Silk Road trade. It was only after Emperor Wu of the Han Dynasty, with the national power accumulated over several generations through a sixty-year policy of rest and recuperation, that a decisive policy of counterattacking the Xiongnu was adopted, hence the ambassadorship of Zhang Qian. When Zhang Qian arrived at the new settlement of Dayue (today's Afghanistan), what caught his attention were bamboo products and textiles from Shu, which the locals told him came from India. The second time Zhangqian went on a second mission, he took more goods with him and sent them to various countries. Although this was not official trade, it facilitated the arrival of tribes and states from the western regions. In this way, the Silk Road was gradually expanded from scratch.

\subsubsection{During Sui and Tang Dynasty.}

During the Sui and Tang Dynasties, Emperor Yangdi planned to explore the northwest territory in military diplomacy, and at the same time sent envoys to communicate with other countries along the Silk Road. During his reign, Emperor Yangdi sent envoys to different parts of the West, opening exchanges with other regions, and obtained agate cups, Buddhist sutras and other rare foreign objects from the Western regions, creating an unprecedented atmosphere of material resources. By the Tang Dynasty, the Silk Road was more prosperous, and the production and trade related to silk and other garments had reached a certain active period. The handicraft industry of Tang Dynasty was divided into two aspects. The products of the official camp were only for the imperial court and the imperial court, while the products of the private sector were sold by the merchants all over the country. Among them, the development of silk weaving handicraft industry in Tang Dynasty occupied an important position in the history of handicraft industry. In Tang Dynasty, there were a lot of high-quality textiles, such as satin, light weight (the lightest yarn) and red carpet, etc. The high level of material civilization and high level of culture also made Chang 'an of the Tang Dynasty become a political, economic and cultural center in the world at that time. In the world, the level of economic and cultural development ranked the top in the world, and it was the Tang Dynasty of China at that time.

\subsubsection{During Song and Yuan Dynasty.}

During the Song Dynasty, the northwestern region was in the hands of the Western Xia Dynasty, and maritime trade flourished as a result. In the thirteenth century, the Mongol Empire established a great empire spanning Europe and Asia. Trade between East and West was also at an all-time high, and it was from this route that the famous Italian traveler and merchant Marco Polo's family came to China. The most prominent descriptions of China in Marco Polo's Travels focus on the economy, commerce, road routes, and topography, reflecting the author's primary interests as a merchant. He mentions not only gold, silver, precious stones, pearls, salt, rice, grain, rhubarb, ginger, sugar, and spices, but also porcelain, textiles, and silk, which were of interest to him.

During the Mongol Yuan Dynasty, the Mongols launched three western and southern expeditions and greatly expanded their territory, which, together with the establishment of post roads and the restoration of the Eurasian transportation network, led to the flourishing of international caravan traffic over a vast area of Europe and Asia. During this period, the Silk Road was open, economic exchanges at various levels in Eurasia flourished, and a number of trade centers, such as national commodity markets and distribution centers, were formed and developed accordingly. The Travels of Marco Polo devoted a chapter to the flourishing international trade of the Yuan dynasty: "All the most precious and precious things of the world can be found in this city, ...... where more commodities are sold than anywhere else". The undisputed status of the Yuan dynasty as the center of international trade in the East is almost universally documented in Chinese and foreign history of the Yuan dynasty. The Yuan dynasty inherited 
and perfected the policy of opening up to the outside world that had been in place since the Tang and Song dynasties, strengthened political ties with overseas countries, and actively pursued overseas trade economically, which also brought the Maritime Silk Road to its peak and laid the foundation for the great voyages of the Ming Dynasty navigator Zheng He.

\subsubsection{During Ming and Qing Dynasty.}

During the Ming Dynasty, the silk Road, with its long history, was in decline as nomadic peoples constantly attacked each other and occupied some parts of the Asian continent, wars continued, and traffic was blocked by many closures. Road traffic is clogged, but sea traffic has made further progress. In history, the Ming Dynasty sent Zheng He to lead an immense fleet on seven voyages to the Western Seas, a series of actions that added to China's remarkable contributions to sino-foreign relations and to maritime history. Zheng he's mission was to expand his political influence, to trade with other countries, and perhaps to find out the whereabouts of Emperor Jianwen. Most of all, it was to develop overseas trade. This new mode of trade helped to spread Chinese culture and technology abroad rapidly. During the Ming Dynasty, Chinese culture spread to the South China Sea through the relocation of a large number of overseas Chinese, most of whom were experienced working people with rich production tools and production techniques, such as iron hoe, iron plough, mining law, etc., which were of great benefit to the people of the South China Sea. In the Qing Dynasty, the Ancient Tea-horse Road and the Silk Road were connected, which further connected the central Plains culture with the central Asian culture and even the European culture, and promoted the integration of multiple cultures.

\subsection{The development of Silk Road culture in different periods}

\subsubsection{Material culture.}

Silk is one of the most characteristic oriental products and an important product that contributed to the smooth flow of the Silk Road. Archaeological findings show that, in the late Neolithic period, there was a sericulture industry in China, with the continuous improvement of technology, silk products have been very exquisite, for the surrounding communities and tribes admired. A silk blend of bird's hair unearthed in the Western region during the Tang dynasty was as thin as paper, as bright as a mirror, and weighed no more than two taels after folding, showing a variety of different patterns from different angles. They reflect the people of the western countries at that time on the silk fabric valued and love. Since then, to grow mulberry-fed silkworm places, has begun to pay a lot of attention to the introduction of Chinese silk spinning technology. Near present-day Xi'an, a number of coins from the Persian and Eastern Roman empires have been unearthed, reflecting the widespread exchange of goods between East and West at that time. In Chang'an, Luoyang, and Guangzhou, a large number of hu merchants emerged. They opened many shops from making and selling hu cakes to jewelry and musical instruments, and some of them stayed away for many years, considering China as their second home. Behind the silk exchange was the great convergence and integration of the world's material resources. Marx pointed out that material is the first need of mankind, without material, mankind will not survive. The exchange of material resources is the cornerstone and driving force of human civilization. It is the differences between the Eastern and Western civilizations and the complementary nature of material resources that have made the Silk Road glorious.

\subsubsection{Dissemination of religion.}

The greatest impact of the Silk Road on human civilization lies not only in the circulation of goods, but also in the fact that the people who traveled along the Silk Road sowed their respective cultures like seeds along the way, including ideas, beliefs, technologies and their material manifestations. Thus, the Silk Road was a path of passage and exchange between civilizations throughout human history. This road has facilitated the spread and exchange of various ideas and religions, and many religions have coexisted in harmony on the Silk Road. Confucianism, the representative thought of China, has been spreading to its neighbors since the day it was born. After Emperor $\mathrm{Wu}$ of Han Dynasty revered Confucianism alone, Confucianism, which had become an ideology, accelerated its spread to neighboring countries. Religion belongs to a special cultural category, which is a kind of spiritual belief and spiritual civilization of mankind. In the seventh century, Xuanzang, a Buddhist monk who wrote the famous "Journey to the Western Regions of the Great Tang Dynasty," was buried in Xi'an's Xingjiao Temple. up a piece of treasure." For 1,300 years, the Hindu Temple has been a major Buddhist shrine in China.

\subsubsection{Artistic Exchange.}

Art is not only the best form of expression of human emotions, but also the highest form of creation of human civilization. Almost all types of art created by mankind, such as bronze, painting, sculpture, architecture, calligraphy, music, dance, etc., have been on the Silk Road to start, exchange and influence each other. As an important part of China's cultural development, the art of Buddhist figurative art was introduced to the east with the spread of Buddhism during the Wei, Jin and North-South dynasties, along with the carving techniques and expressions of ancient Greece. Due to the hot weather in southern India, people wore little clothing, so they naturally absorbed and borrowed the artistic style of the ancient Greek goddesses of water and applied it to the presentation of Buddhist statues. The Buddha's coat was thinner and his torso more prominent. The Buddha's coat was thinner, the limbs and torso more prominent, the figure seemed to have just come out of the water, there 
was hardly a thread of clothing, the robe was completely attached to the body, the figure was almost naked. This style was then imported to the Western region, where the figures in the Gaochang Buddhist tales of Buddhist offerings to the Buddha are plump, dressed in a throughthe-shoulder robe with a thin, silk-like garment that hangs close to the contours of the body, showing the fine lines of the garment. During the Sui and Tang dynasties, in the early Tang dynasty in Mogao Caves in Dunhuang, the bodhisattva is in graceful posture and proportion, with a thin, transparent dress that fits the body and a smooth, rounded pattern. In the Bingling Temple Caves, the Buddha of Immeasurable Life, although still dressed in the typical thin, through-the-shoulder robe, began to incorporate features of the Chinese people and culture. This style influenced the style of Buddhist statues in the Central Plains, such as the Yungang Grottoes, the Longmen Grottoes, and Guangyuan in Sichuan, and fully influenced the artistic style of Buddhist statues in ancient China, which in turn influenced painting, forming the Chinese style of "Cao Yi out of water".

On this ancient road, silk from the Middle Kingdom was introduced to the West, while jade and other luxury goods from Hotan, glassware, silver and other ornaments from the Mediterranean, and horses and furs from the steppes were introduced to the Central Plains, becoming a unique art form and type on the Silk Road. From this we can see that the Silk Road, the exchange of various materials, objects and their forms of entertainment activities, but also constantly changing our "art" of materials and means, content and form, function and function, concepts and ideas, not only continue to define our definition of "art", but also continue to expand our awareness of "art", but also continue to expand and enrich the cultural implications of the Silk Road.

\subsection{Silk Road Cultural Development in Different Regions}

\subsubsection{Northern China.}

The Northern Silk Road, or Silk Road for short, refers to the Silk Road in the Western Han Dynasty (202 B.C.-8 A.D.). It refers to the Western Han Dynasty (202 B.C.E. 8 A.D.), opened up by Zhangqian's expedition to the West with Chang'an (present-day Xi'an) as the starting point, through Gansu, Xinjiang, to Central Asia, West Asia, and connecting the Mediterranean countries of the land passage, China's early Silk Road originated in Sichuan, is the "Southern Silk Road." The Silk Road opened up by Zhang Qian in the Han dynasty went northward and can be called the "Northern Silk Road". Shaanxi, as the starting point of the Silk Road, is also the center of China's western economic belt. The Guanzhong Plain in central Shaanxi has many prehistoric sites, dynastic artifacts and historical relics, and can be called the cradle of Chinese civilization. From the 221 B.C. Qin and Han dynasties to the height of the Han and Tang dynasties, numerous ruins and relics bear the memories of the development of Chinese civilization, such as the ancient city walls of Xi'an and the Xingjiao Temple
Pagoda. Another important province is Xinjiang, which, as a necessary pass on the Silk Road in northwestern China and a window for East-West exchanges, has a long and stretched border with eight neighboring countries. The history and culture of Xinjiang can be described as a history of the rise and fall of the West, and its rise and fall are inseparable from the Silk Road. At the same time, as a key region where East meets West, Xinjiang's religions are also characterized by pluralistic coexistence, and their historical processes have promoted the historical development of northern China and western China and the development of the Silk Road.

\subsubsection{Southern China.}

Hundreds of years before Zhangqian's expedition to the West, there was already a road connecting the Chinese people to other peoples, this road is called the "body poisoned Shu Road", also known as the "Southern Silk Road", this ancient road is more than 2000 kilometers long, is a Originating in Sichuan, passing through the Yunnan and Guizhou plateau, the road to the South Asian subcontinent and the central and southern peninsula, it introduced the culture of the southwestern frontier region to the central and southern peninsula region, promoting the exchange of these ancient peoples. The Southern Silk Road reached the Central Plains in the east and India in the west, and the cultures of the Central Plains and India interacted with each other and had a profound influence on the cultures of the Southwest through this road. "Its price as gold" of Shu brocade, thicker texture, smooth surface, lustrous, unprecedented production in the Han dynasty, the Sui and Tang dynasties, the scale was even larger, the quality of good, famous for the world, known as one of the East. Westerners began to know China through the silk of this commodity, the understanding of Eastern civilization. The introduction of Buddhism into China was very popular along the ancient route, and was more prevalent in the culturally developed Dianchi region and the Erhai region, especially in Dali, which reached its heyday in the Song Dynasty. The introduction of Buddhism made Yunnan's sculpture and painting art also integrate into Buddhist culture, so in the Dianchi and Erhai regions, there were a number of stone carvings of high artistic standards, such as the Jianchuan Shi Zhong Shan Grottoes, Jianchuan Jinhua Temple Mountain cliff carvings. Southern Silk Road is a cultural spread of the link, it is linked to the Central Plains, China and India, it is for the Central Plains, Southwest, India and Myanmar cultural exchanges, mutual integration of conditions created, Chu culture, Shu culture, bronze culture, Buddhist culture in the exchange of precipitation, accumulation, and thus the formation of a rich, unique and cohesive characteristics of the ancient road culture.

\subsubsection{Central Asia.}

The Central Asian region is ethnically diverse, mainly comprising Ukrainians, Turkmen, Uzbeks, Kazakhs, etc., and in general it has a more nomadic culture because of the high level of migration flows in the region. The 
interweaving of Central Asian peoples and Silk Road culture has led to the world-famous animal husbandry culture (the most famous being horse culture), Kazakh dance culture, and carpets with the characteristic patterns of Central Asian peoples in Central Asia. In addition, Central Asian civilization is deeply influenced by Islamic civilization, Chinese civilization, Indian civilization, two rivers civilization, ancient Greek and Roman civilization and many other civilizations, is the middle zone of the Silk Road in the exchange of civilizations and coprosperity, in the hinterland of the Eurasian continent, deep inland, and with China's western border, transportation, frequent economic exchanges, the extension of the Silk Road has an important significance. The region is rich in natural resources, with a lot of deserts and grasslands, high mountains and snow peaks, lakes and scenery, and a variety of original ecological natural landscape, as well as Silk Road towns.

\subsubsection{West Asia and Eastern Europe.}

The Western Asia region is one of the ancient cultural centers of the world, connecting the Eastern European region, which includes countries such as Iran, Iraq, Jordan, Syria, Saudi Arabia, and Turkey, Azerbaijan and Armenia in the Caucasus, and Ukraine and Belarus in Eastern Europe. The former is primarily an Arab cultural zone, while the latter is a border zone of Eurasian culture. These countries of the former are Islamic cultural zones and their customs and habits exhibit a unique exotic Arab culture. Among them, Iran, the seat of ancient Persia, has world cultural heritage sites such as the Persian Garden and Chagao-Chambier (sacred towers and complexes). Among them, Iran, the location of the original ancient Persia, has been in contact with ancient Persia since 1000 B.C. The Silk Road has been the link between China and ancient Persia. Silk, the main character on the Silk Road, was introduced to Persia through the northern grasslands of Central Asia, and as a result of Zhangqian's expeditions to the west during the Han Dynasty, China's relations with Persia deepened. As China has other countries can not surpass the sericulture technology, making Persia attach more importance to dealings with China, Persia as a hub of East-West trade exchanges attach great importance to the silk trade, especially in recent years in China unearthed a number of local Persian silver coins in circulation at the time, enough to see the Persian merchants at the time with China's active trade in goods, the development and circulation of silk for the silk played a guide and It also plays an important role in promoting multicultural heritage and progress.

\subsubsection{European region.}

As the westernmost part of the Silk Road, the European region played an even more integral role. Its end point was ancient Italy, the Roman Empire, and according to historical records, the high society of ancient Italy, and indeed all of Europe, was proud to wear silk from China. After the two Han dynasties, glassware, gold and silverware from Rome continued to be imported, and raw silk and silk products from China continued to be exported. The introduction of silkworms and silk reeling techniques enabled the Italian silk industry to develop independently, and the popularity of paper making and printing enabled a large number of books to be circulated, promoting cultural and academic development. Especially located in central Italy, Lucca, the silk trade made Lucca become a famous city in the Middle Ages, the development of Lucca in the 14th century reached its peak, is the whole of Europe's silk town and the Italian textile center, the city still retains the remains of the dyeing and reeling workshop.

\section{China's silk development history of research - the research and analysis of Suzhou Silk Museum}

More typical in China to show the development process of Chinese silk is to be a number of Suzhou Silk Museum, through research and introduction of the Silk Museum's historical background, functional space layout and reflect modern cultural and artistic installations, to summarize and analyze the overall development process of silk and silk culture combined, and then to do the empirical analysis for the back of the research example paves the way.

\subsection{Silk Museum's historical background}

Suzhou Silk Museum is located in the Beisi Tower Scenic Area in Suzhou, Jiangsu Province, is a silk professional museum, by the famous silk expert Qian Xiaoping initiative and created. In the "Belt and Road" the background of the times, Suzhou Silk Museum to the new Silk Museum, the new pursuit of new dreams for the goal, play the traditional advantages, strengthen service functions, to create new highlights, operation and management of further professional standardization of modernization, in the display and exhibition, social education, publicity and promotion, basic business and other aspects of efforts to improve, in order to expand the influence of the industry, increase social awareness, raise the banner of Suzhou Silk.

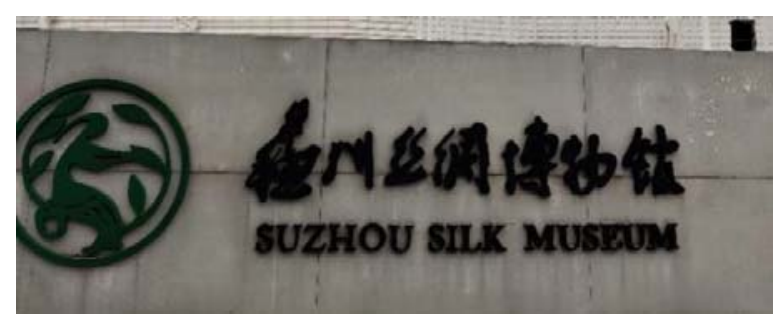

Figure 1: Suzhou Silk Museum doorplate 


\subsection{Introduction to museum functions and spatial layout}

\subsubsection{Reflecting the far-reaching history of Suzhou silk culture - History Museum.}

History Museum is the key exhibition hall of the research, but also the core of the Silk Museum. Display space, boutique through the cabinet, monument reproduction, painting creation, modeling panels with a time sequence of cultural relics on display, multi-level gradually to support the historical status of Suzhou Silk, so that visitors intuitively feel the weight of Suzhou Silk history and culture.

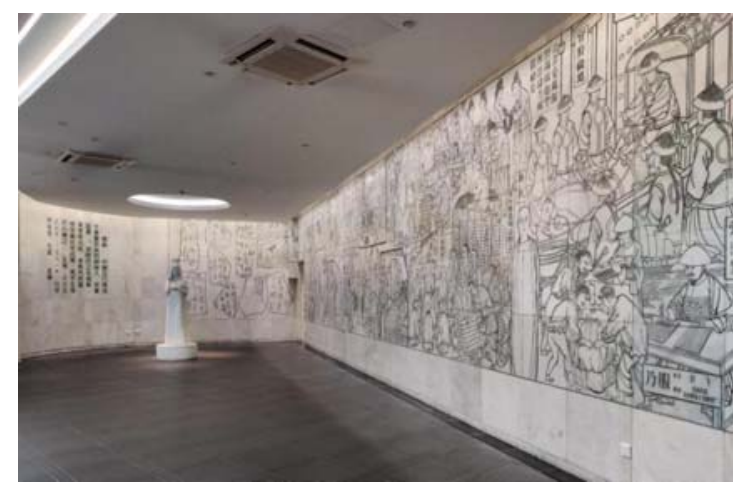

Figure 2: Statue of Rayon and relief sculpture in front of History Museum

The history museum consists of six sections: Ancient Hall, Silkworm House, Dyeing and Weaving Workshop, Tribute Weaving Institute, Republic Street and Nonheritage Hall. Entering the exhibition hall, text, objects, replicas, simulated scenes, multimedia and other means of display is very rich, reproduced and Suzhou city coexist with a history of the development of silk in Suzhou.

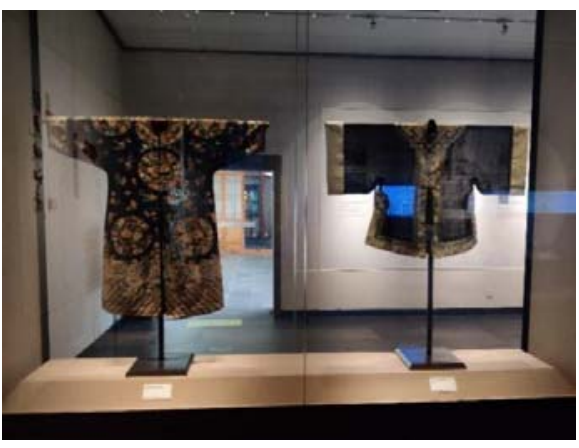

Figure 3: Ancient silk garments display

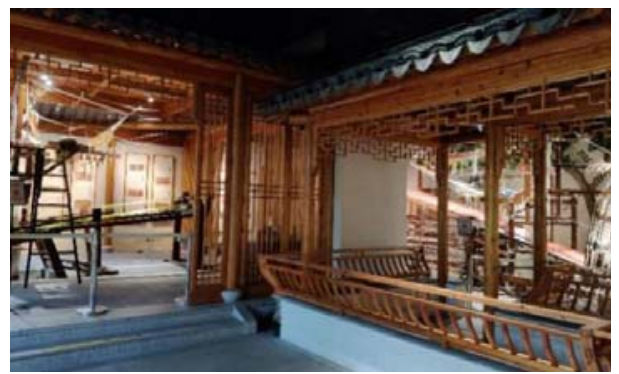

Figure 4: dyeing workshop

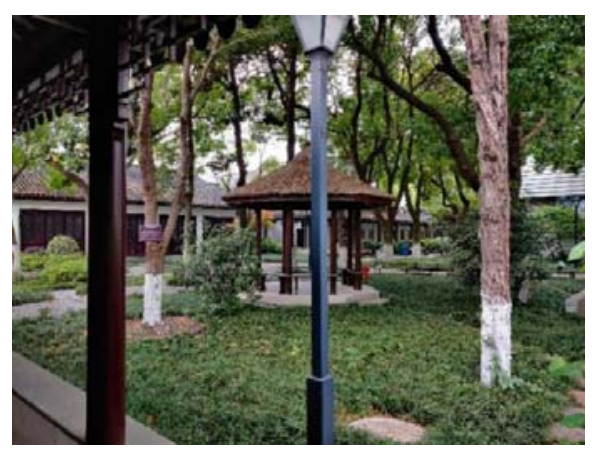

Figure 5: Backyard

\subsubsection{Suzhou modern digital silk technology on display - Modern Pavilion.}

From the 60 s to the 90 s of the last century, Suzhou silk industry unprecedented prosperity, emerged a number of "four silk factories" such as Suzhou Zhenya Silk Mill, Suzhou Dongwu Silk Mill, as represented by the outstanding silk enterprises. That a piece of fine fabrics, a piece of silk samples, as well as the elegant and plain Diana Princess of silk taffeta wedding dress, are interpreted as the glorious achievements of Suzhou silk enterprises. As the darling of the fashion world, silk is also popular with designers, Modern Silk Museum using large multimedia show on the fashion stage silk fashion show, while showing modern digital silk technology, new technology and new varieties as well as corporate donations of silk boutique.

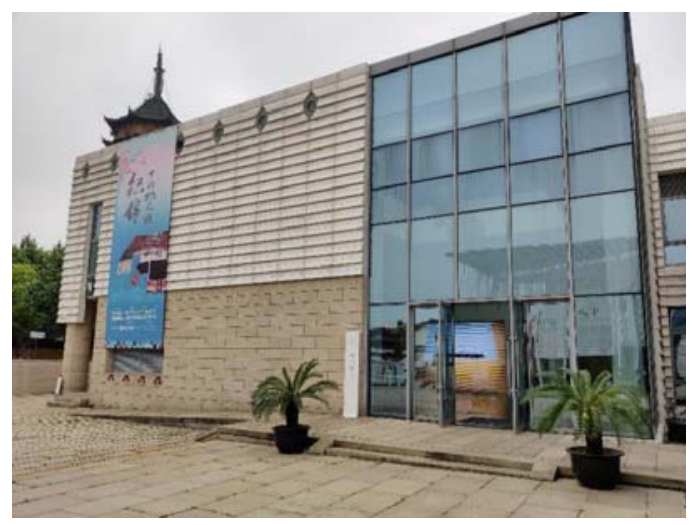

Figure 6: Exterior of Modern Hall

\subsubsection{Expansion of children's knowledge of silk weaving - Children's Science Popularization Experience Center.}

The General Science Museum for Children covers an area of 360 square metres, which is a new venue added in the renovation and upgrading project. The museum is designed with the concept of edutainment in mind, with flexible teaching forms that bring science knowledge and minors closer together, and touch screen and other multimedia technologies that make visiting and learning interactive. Suzhou Silk Museum, as a popular science education base in Jiangsu Province, Suzhou patriotism education base, in the ideological and moral construction of minors bear an important responsibility. 


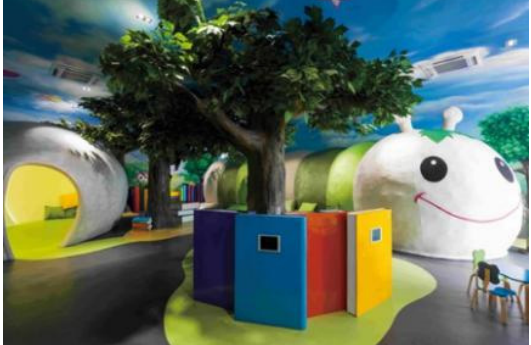

Figure 7: Children's Hall Stairs

\subsection{Modern Cultural Art Installation in Suzhou Museum}

There is a striking art installation on the square in front of the history museum, which is a modern installation named "The Rain of the Four Directions" created by Japanese architect Matsubara Doppo specially invited by Shanghai Ruihe Design, who is responsible for the exhibition design of the history museum. The threaded rain is intercepted into a quadrangle shape and appears to be floating in the air. The silk threads could be faintly heard through the wind. Like pearls reflecting the sunlight, countless clusters of light decorated the silk road. Under the sunlight, the ground takes on the shape of a structure like the warp and weft threads of silk fabric. The façade has been modernized by replacing the façade materials while respecting the original architectural design. The combination of the installation and the façade is indeed very eye-catching in the old city. Although it is a modern form, it is eye-catching without being awkward because it echoes the original building in terms of color and material, and the surrounding buildings have been renovated.

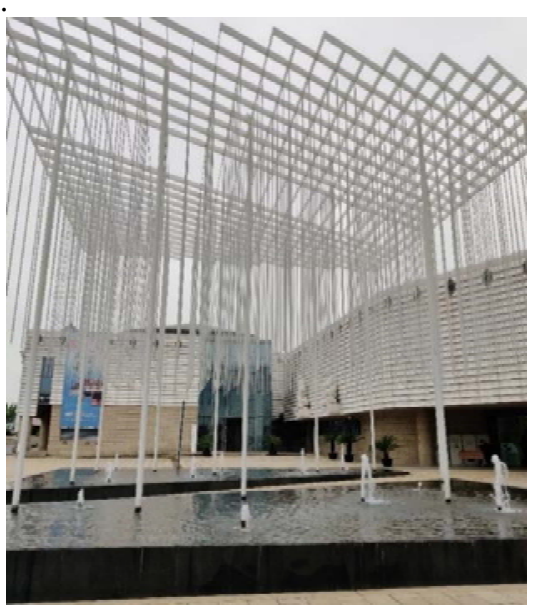

Figure 8: Installation "Rain in the Four Directions" in Museum Square

\section{Reflections on the application of Silk Road culture to landscape design}

Through the research and understanding of the different dimensions of the Silk Road culture, as well as the field research and analysis of the Suzhou Silk Museum, we summarize and consider the application of the design concept in the campus landscape case.

\subsection{Belt and Road Innovation Heights: Western China Science and Technology Innovation Port}

West China Science and Technology Innovation Port is located on the south bank of the Weihe River in Fengxi New City, Xi'an, Shaanxi Province, which is a major project organized and implemented by Xi'an Xi'an New Area and Xi'an Jiaotong University and included in the "One Belt, One Road" strategy, adjacent to the Weihe Ecological Zone and surrounded by wetland parks and outdoor sports parks (Figure 2). The supporting facilities are advanced and the environment is beautiful. President Wang Shuguo of Jiaotong University once said that Xi'an Jiaotong University is determined to use this new and modern platform to lead innovation in western China. Nowadays, in the Innovation Harbor, the headquarters of "Silk Road University Consortium", which is jointly listed by 135 universities from 35 countries and regions, has been built and introduced, and several international joint laboratories and well-known universities have established mutual aid organizations in the Innovation Harbor. At the same time, well-known enterprises at home and abroad have also promoted a series of cooperation with Innovation Harbor, jointly promoting the cultivation of innovative talents and laying a certain foundation for the construction of innovation industrial base.

It can be seen that the construction of the innovation port has a significant role in promoting the advancement of some parts of the country. As the campus of Xi'an Jiaotong University, the Innovation Port is full of leading, innovative and advanced sense, and is located on the starting point of the Silk Road, which needs to embody the Silk Road culture and make the teachers and students have the responsibility to inherit and appreciate the Silk Road culture, so that the diversity of civilization and culture of the Silk Road can be carried forward and spread in the Innovation Port and embedded in the campus life of the university.

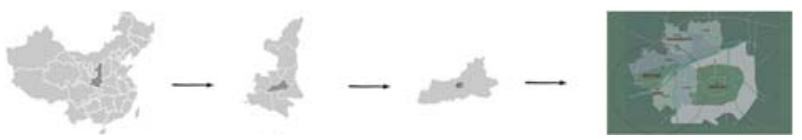

Figure 9: Geographical location of the West China Science and Technology Innovation Port (Author's drawing)

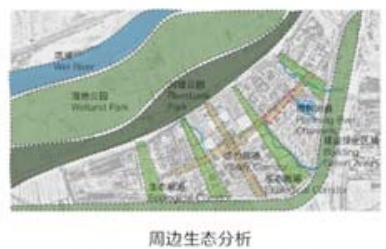

Peripheral Ecological Analysis

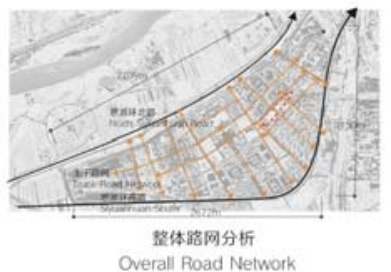

Overall Road Network
Figure 10: Overall analysis of West China's science, technology and innovation port (Author's own drawing)

\subsubsection{Analysis of the current situation and preliminary concept.}

The design site, with a total area of 1.9 hectares, is located in the eastern part of the Innovation Harbor, 
adjacent to the textbook and research center structure to the north, commercial and residential areas to the south, the school landscape to the west, and residential areas to the east. After analyzing the surrounding area and the direction of pedestrian traffic, the area is roughly divided into zones and road directions.

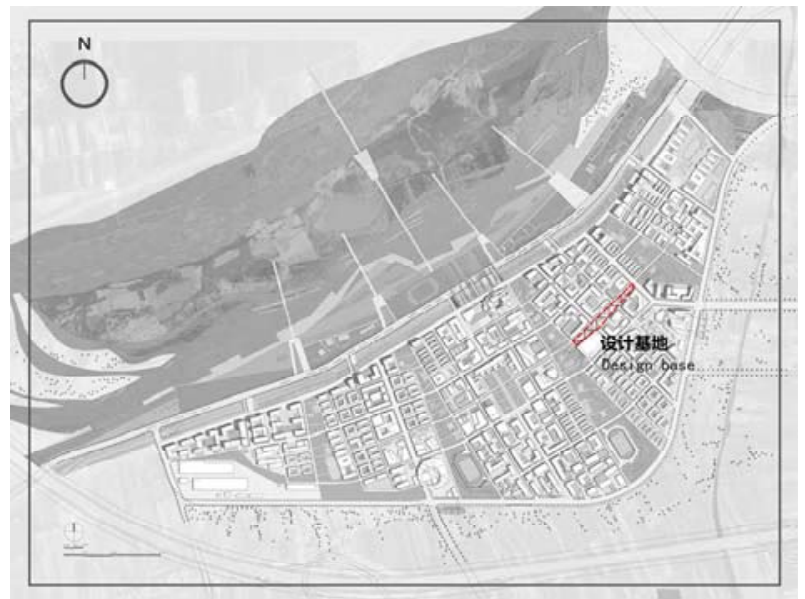

Figure 11: Geographical location of the design site (author's own drawing)

\subsection{Design concept of Silk Road cultural landscape imagery}

\subsubsection{General cultural imagery.}

Through the extraction and application of the overview of Silk Road culture, which is reflected in the campus landscape, and the advantageous geographic location and human conditions, the design will combine physical and spiritual images to create the continuity of the cultural context and the spiritual level that can be subjectively felt through the inheritance of the cultural mood.

\subsubsection{Road construction and connection layout.}

The curves and circles are combined to form a streamlined and smooth road, which is in line with the aesthetic characteristics of linear shape.

\subsubsection{Node elements and functional space.}

To simplify and summarize the elements of the Silk Road, construct landscape nodes, such as: hump leisure space, ribbon seats, mesh green space and other nodes, taking into account the deeper meaning of the elements, the nodes of the landscape as real, cultural symbols as virtual, virtual and real organic combination, giving each node space for multiple leisure and use of functions, leading people to think about and understand, to appreciate the diversity of spatial experience.

\subsubsection{Plant selection and ecological configuration.}

Plants play a very important role in landscape design. Under the premise of creating cultural imagery, the beauty of plants is close to their spiritual connotation, and two aspects should be considered in the selection of their forms, types and colors. The first is to consider the aesthetic relationship between the plant species and the surrounding site, and the second is to consider the close relationship constituted between the plants themselves. Therefore, we choose plants that traveled on the Silk Road, such as mulberry trees, grapes, pomegranates, mandarins, etc. These plants were introduced to China from the Silk Road and have historical origins.

\subsection{Extraction of cultural elements of the Silk Road and application of landscape space}

\subsubsection{Multiple extraction of elements.}

In the modeling element, by extracting the fluidity of the silk material and the undulation of the ribbon, the landscape seat is applied to make the user feel the silk road style, and the image of the continuous desert and the undulating camel's hump are chosen to set up the undulating grass slope and the landscape seat. In the path element, the grid shape of the whole silk road and the leaf shape of tea leaves in the tea culture are extracted and combined with the silk road coins for the path design. In the physical element, the most common and widely used pattern of "grapes" in silk products is extracted, which is full of the elegant beauty of Chinese elements.

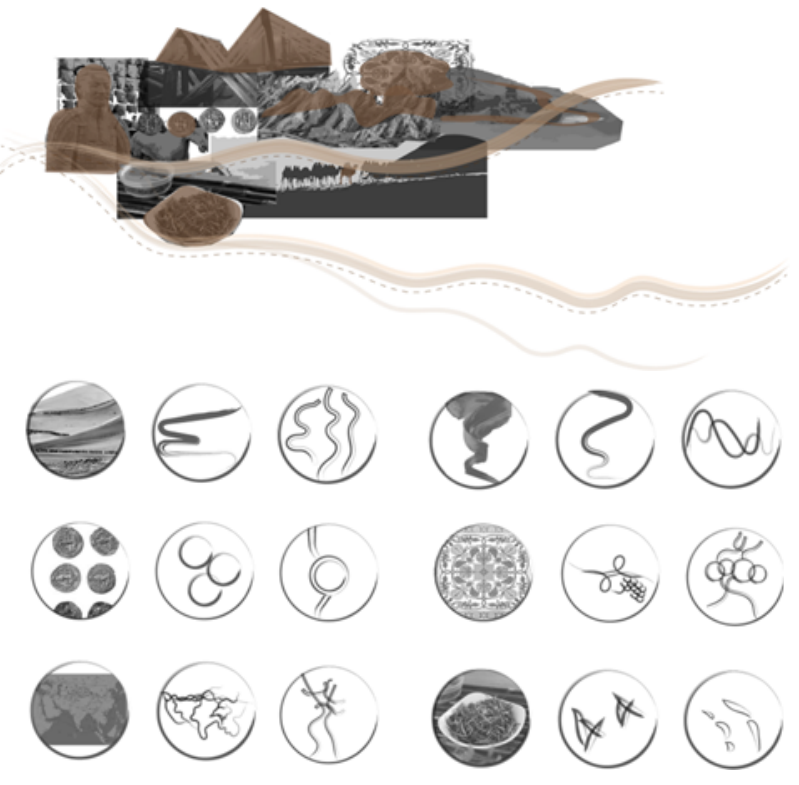

Figure 12: Extraction of Silk Road Elements
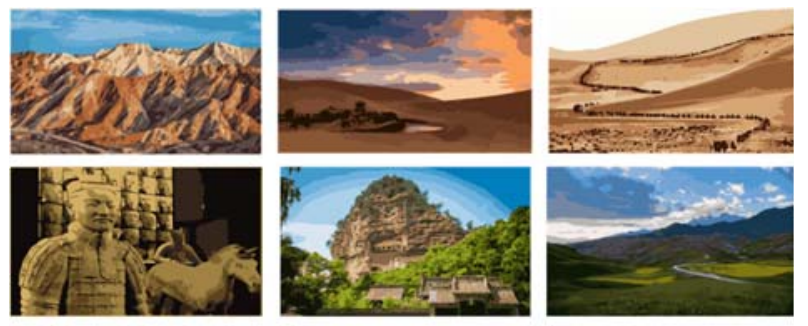


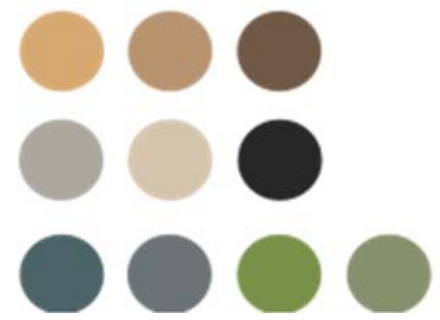

Figure 13: Extraction of Silk Road color elements

\subsubsection{Proposal presentation and design concept.}

The scheme is based on the principles of humancenteredness, natural ecology and cultural heritage, and the common points of the Silk Road culture are extracted and applied to the design. In the form of the road, the flowing sense of silk, the leaf shape of the main trade commodity Chinese tea and the round shape of the Silk Road coins with rich cultural connotation are extracted, using curves and circles in the form of staggered loops, which symbolize the different branches of the Silk Road, and set up interspersed Silk Road walkways to increase the convenience of transportation and multiple feelings of sightseeing. In the plaza and water feature area, ribbon seats and streamlined landscaping pieces are set up, and floating islands in the shape of tea leaves are set up in the river to symbolize the transmission of silk culture and tea culture to the world. In the recreation area, the pattern of "grapes," the most common and widely used pattern in silk products, is conceptually captured and applied to the enclosed space of the tree pond and chairs, reflecting the connotation of traditional Chinese elements. In addition, the undulating grassy slopes and humped seats are installed to represent the continuous mountain and desert scenes that are common along the Silk Road.

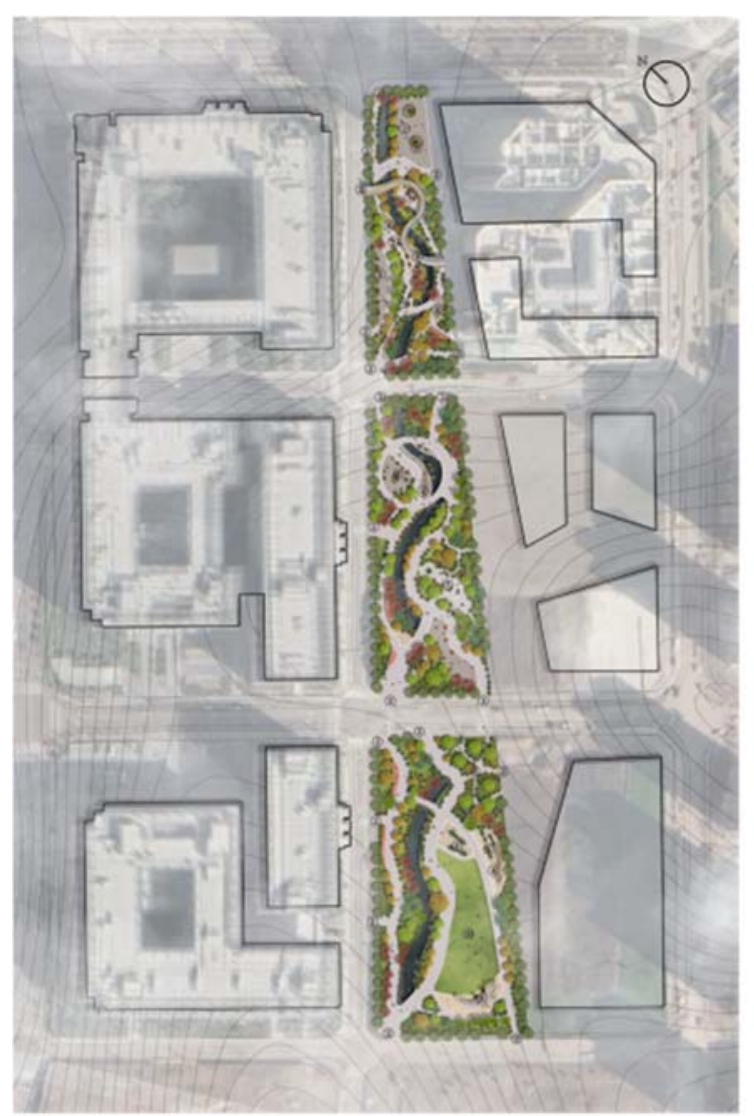

Figure 14: Schematic design plan

Good creation of space in the landscape occupies a very important position, the design of the overall landscape level of undulating and winding continuous, visually hidden and show part of the scenery, so that people in which to visit full of curiosity, and to increase the fun and deep mood of the space. As shown in the figure, there are six main types of space: semi-enclosed space, enclosed space, interspersed space, rising space, sinking space and a combination of rising and sinking space.

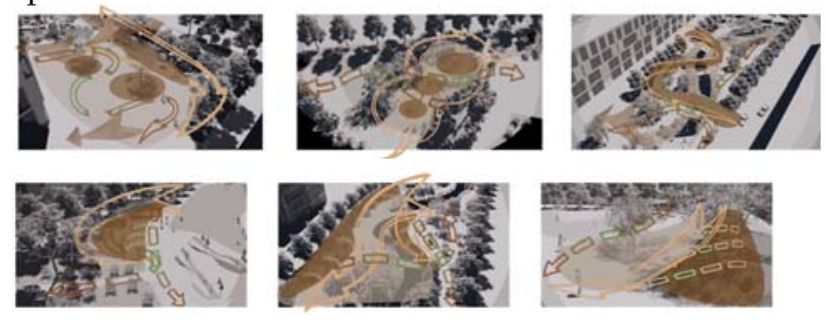

Figure 15: Six types of venue space creation

In the selection of landscape configuration of the site, nine kinds of plants that traveled through the Silk Road were selected, including fig tree, grape tree, walnut tree, coriander from the Mediterranean coast, sunflower from Central and South Asia into China, clover and pomegranate tree from ancient Persia, nectarine from India and red and blue flowers from the West into China, and combined with common plants in the campus landscape, from the space, ecology and culture of the three aspects of reasonable configuration, to build a 
campus green space with rich layers, green ecology and cultural connotation.

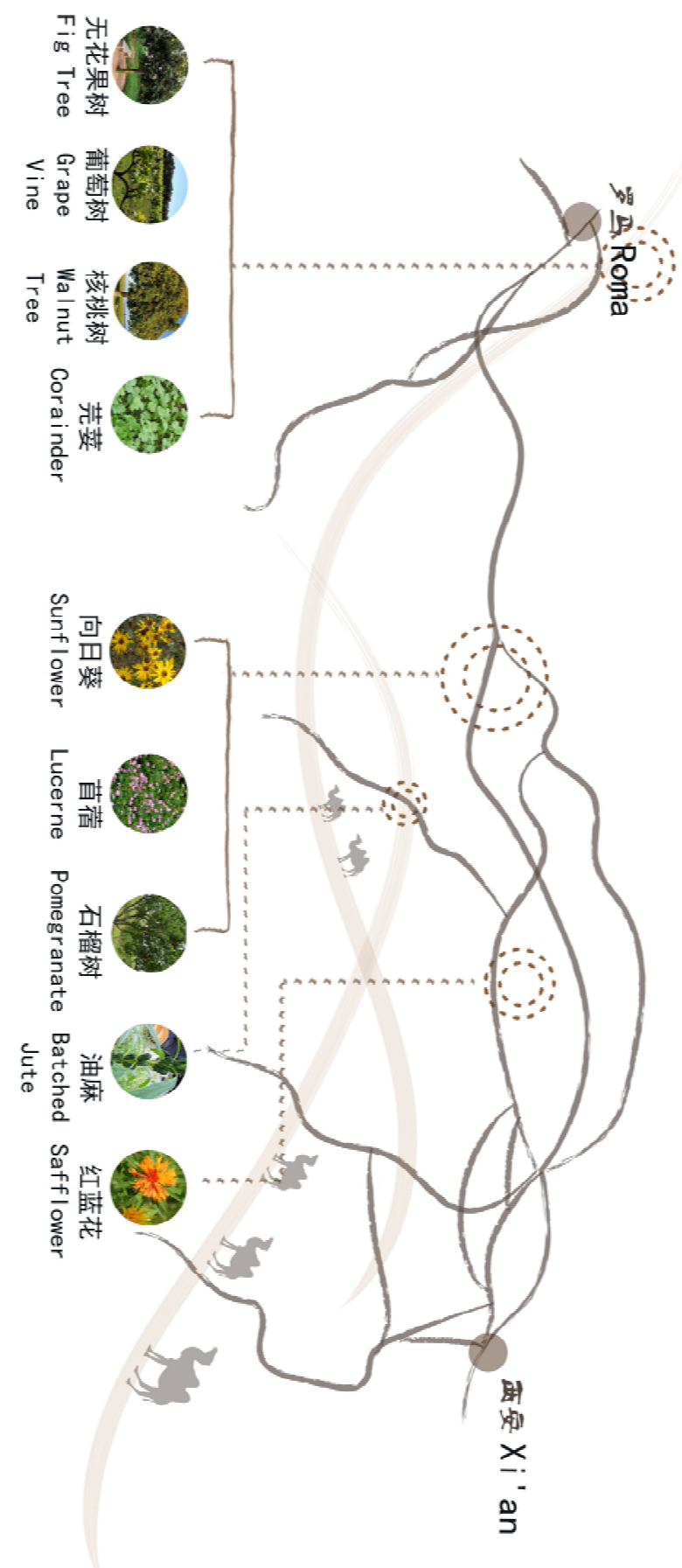

Figure 16: Plant Geographical Selection Map

Table 1: List of plant extracts

\begin{tabular}{|c|c|c|c|}
\hline Plant names & Latin & Genera & $\begin{array}{c}\text { Ornamental } \\
\text { properties }\end{array}$ \\
\hline Fig tree & $\begin{array}{c}\text { Ficus carica } \\
\text { Linn. }\end{array}$ & Moraceae & $\begin{array}{c}\text { Leaf, flower } \\
\text { and fruit } \\
\text { watching }\end{array}$ \\
\hline Grape vines & $\begin{array}{c}\text { Vitis vinifera } \\
\text { L. }\end{array}$ & Vitis vinifera & $\begin{array}{c}\text { Leaf, flower } \\
\text { and fruit } \\
\text { watching }\end{array}$ \\
\hline Walnut tree & Juglans & Pecanaceae & $\begin{array}{c}\text { Leaf and } \\
\text { fruit }\end{array}$ \\
\hline
\end{tabular}

\begin{tabular}{|c|c|c|c|}
\hline Coriander & $\begin{array}{c}\text { Coriandrum } \\
\text { sativum L. }\end{array}$ & $\begin{array}{c}\text { Coriander, } \\
\text { Umbelliferae }\end{array}$ & $\begin{array}{c}\text { observation } \\
\text { flower } \\
\text { observation }\end{array}$ \\
\hline Sunflower & $\begin{array}{c}\text { Helianthus } \\
\text { annuus L. }\end{array}$ & $\begin{array}{c}\text { Platycodon } \\
\text { grandiflorum, } \\
\text { Asteraceae }\end{array}$ & $\begin{array}{c}\text { Leaf, flower } \\
\text { and fruit } \\
\text { watching }\end{array}$ \\
\hline Clover & $\begin{array}{c}\text { Medicago } \\
\text { Sativa Linn } \\
\text { Pomegranate }\end{array}$ & $\begin{array}{c}\text { Clover in the } \\
\text { subfamily } \\
\text { Caddisfly } \\
\text { granatum L. }\end{array}$ & $\begin{array}{c}\text { Leaf } \\
\text { observation } \\
\text { family }\end{array}$ \\
\hline Oilseed & $\begin{array}{c}\text { Sesamum } \\
\text { indicum } \\
\text { Linn. }\end{array}$ & $\begin{array}{c}\text { Sesbaniaceae } \\
\text { and fruit } \\
\text { watching }\end{array}$ \\
\hline Tulipa & $\begin{array}{c}\text { Carthamus } \\
\text { tinctorius L. } \\
\text { and fruit } \\
\text { watching }\end{array}$ \\
\hline & $\begin{array}{c}\text { Eustoma } \\
\text { (Asteraceae) }\end{array}$ & $\begin{array}{c}\text { Flower and } \\
\text { fruit } \\
\text { observation }\end{array}$ \\
\hline
\end{tabular}

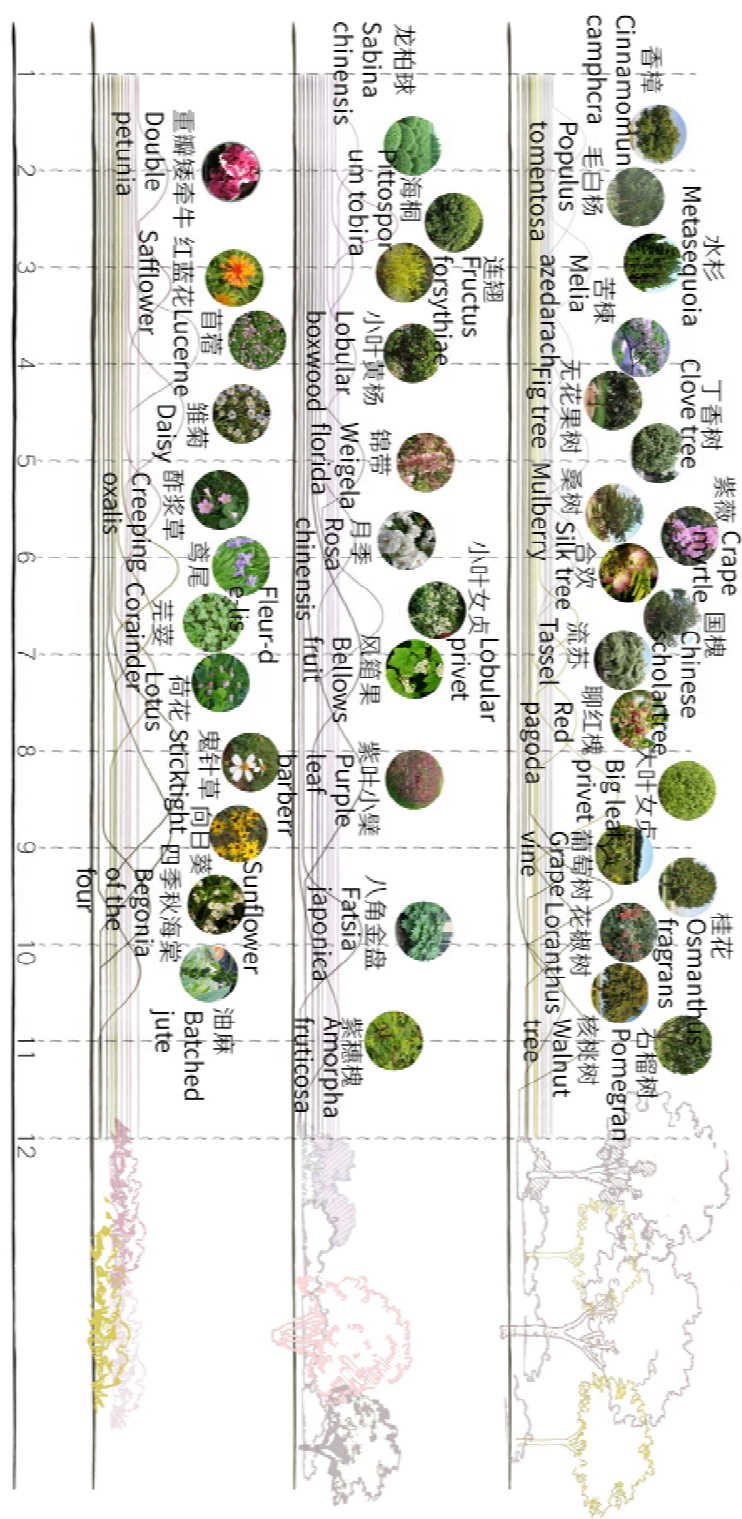

Figure 17: Plant Configuration Chart

The elements are applied to the landscape space, firstly, the brownish-yellow stainless steel silk road 
landscape seats are placed in the cultural leisure square, the overall irregular undulating continuous form is not only interesting but also has cultural charm. In the southern part of the cultural leisure square, there is a silk walkway, the entire section of the overhead yellow, gray and blue color of the undulating curves of the glass barrier, and the leisure space and road system connected to the space, forming an interspersed road space. The middle part of the plaza is a rest space with grape culture and tea culture. The grape texture is extracted and surrounded by greenery, and the curved grass and seats in the middle match to form a semi-private conversation space.

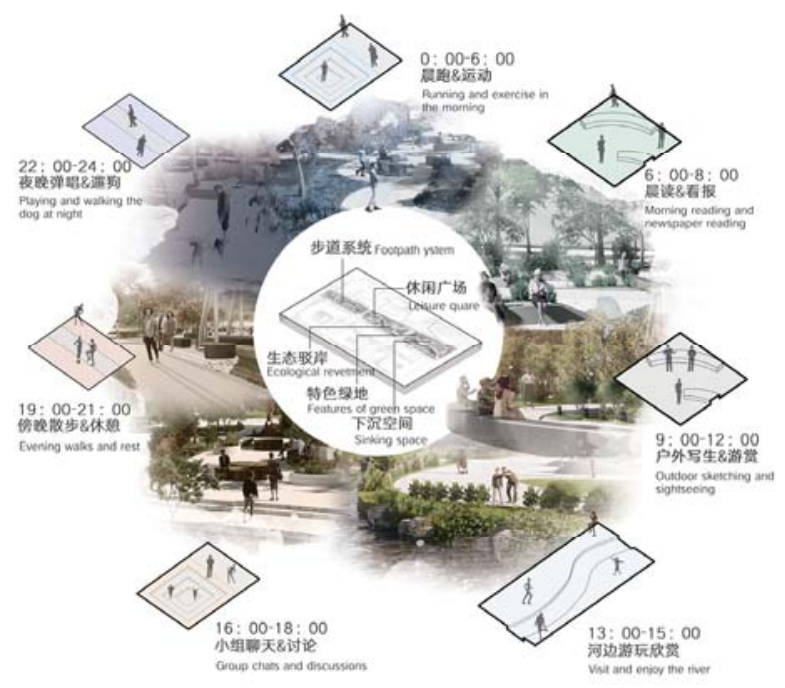

Figure 18: Rendering presentation

\section{Conclusions}

In this paper, first of all, the connection between the Belt and Road and the Silk Road is introduced, then the background and the origin and development of the Silk Road culture to summarize, to understand the different periods, different levels as well as the cultural development of different regions.

Secondly, combined with research and analysis of the case of Suzhou Silk Museum, through an inductive introduction of the historical background of the Silk Museum, functional space layout and reflect modern cultural and artistic installations, to summarize and analyze the overall development process of silk and Silk Road cultural combination, through the Western China Science and Technology Innovation Port's green corridor landscape design describes how to extract the Silk Road elements used in campus landscape design, to create a different level of space, such as enclosed space, semienclosed space, as well as lifting, sinking space, as well as for the space, ecological and cultural characteristics of the green configuration, inheritance of Silk Road culture, show the Silk Road connotation.

\section{ACKNOWLEDGMENTS}

I am a graduate student in Xi'an Jiaotong University. It was a wonderful experience. During my study, I believe that I have gradually mastered how to be an excellent researcher, and my research and mental growth can not be separated from the members of the group and other colleagues and friends. I would like to thank my tutors, my parents and friends for their continuous encouragement in the period of self doubt when I am not smooth. I also want to thank myself for the extraordinary hope, strong optimism and childlike enthusiasm that I have brought to myself. With encouragement, determination and hope, I can and will continue to work hard to do a good job.

\section{REFERENCES}

1. He Ru. Research on cultural exchanges between Chinese and foreigners on the Silk Road of the Tang Dynasty [D]. Northwest Agriculture and Forestry University of Science and Technology, 2014.

2. Peter Frankopan, Shao Xudong, Sun Fang. The Silk Road: a brand new world history[J]. People's Rule of Law,2019(07):108.

3. Hou Can. The meaning, content and method of Silk Road Studies[J]. Silk Road, 1997, (6): 9-10.

4. Liu Yonglian. Cultural return on the Silk Road from silk culture dissemination[J]. Western Studies, 2008,

5. Lv Zhen Gang. A study of the role of Chinese merchants in the construction of the regional trade system between China and Southeast Asia in the Ming Dynasty [D]. Jinan University,2018.

6. Yu Zhiyuan. Jiuquan Silk Road Cultural Tourism Development Research[D]. Xinjiang Normal University, 2004.

7. Liu Yingsheng. Silk Road [M]. Nanjing: Jiangsu People's Publishing, 2014.

8. Wang Jizheng. On the etymology of the term "Silk Road"[J]. Journal of Dunhuang Studies, 2015, 1(02):21-26.

9. Xue Dongqian, Shi Ning, Duan Zhiyong, Guo Jing, Li Ling. Channels of Cultural Exchange, Dissemination and Diffusion - Taking China's Silk Road as an Example[J]. Journal of Northwestern University (Nature Science), 2013, 43(05):781-786.

10. Chang Junli. A study of campus landscape in Chinese and Western universities[D]. Nanjing Forestry University, 2013.

11. Du Jibao. A study on the evaluation of plant diversity and beauty of campus greenery in Zhengzhou University[D]. Henan Agricultural University, 2009.

12. Li Lin. "Cultural route" and "Silk Road" cultural heritage protection analysis[J]. Xinjiang Social Science, 2008(03):95-99+128.

13. Qiu Yuhua, Chen Youlin. The expression of cultural connotation in university campus landscape 
design[J]. Journal of Huazhong University of Science and Technology (City Science Edition), 2007(02): 74-77.

14. Guan Chong. Research on green space system planning on university campus[D]. Northeast Forestry University, 2006.

15. Shen Jie. On the ecological view of landscape in campus planning[J]. Journal of Architecture, 2005(03): 31-33.

16. Zhang Chunhui, Wang Xianjie, Wang Daqing. Planning and design of green spaces on university campuses[J]. North Horticulture, 2004(04):52-53.

17. Zhang Chunhui. Research on Landscape Planning and Design of Green Space in University Gardens[D]. Northeast Agricultural University,2004.

18. Bai Han. Landscape Exploration in University Campus[D]. Beijing Forestry University, 2004.

19. Wang Xiao. The cultural value of tourism on the Northwest Silk Road and its development[D]. Shaanxi Normal University, 2004.

20. He Lei. Inheritance and development of Buddhist image making art[J]. Popular Literature and Art,2016(21):109.

21. Zhen LI. Research on the Creation of the Cultural Atmosphere in Modern Campus Design[C]. Advanced Science and Industry Research Center. Proceedings of 2017 International Conference on Advanced Education and Management Science (AEMS 2017). Advanced Science and Industry Research Center: Science and Engineering Research Center, 2017: 111-115.

22. Herbert. A.Simon, an empirical science Artificial Intelligence[J]. Artificial intelligence 1995(77): 95127.

23. Gopal M. The Silk Road -- a Cultural Thread Connecting Asia. Economy, Culture \& History Japan Spotlight Bimonthly. January 2017:56-59. 